\title{
Hemophagocytic Syndrome Associated with Hodgkin's Lymphoma First Presenting as Fever and Pancytopenia
}

\author{
Ramon Andrade Bezerra de Mello, ${ }^{1,2}$ Elsa Fonseca, ${ }^{3,4}$ Manuela Brochado, ${ }^{5}$ \\ and João Manuel Quinaz ${ }^{1,2}$ \\ ${ }^{1}$ Internal Medicine Department, São João Hospital, 4200-319 Porto, Portugal \\ ${ }^{2}$ Department of Medicine, Faculty of Medicine, Porto University, 4200-319 Porto, Portugal \\ ${ }^{3}$ Surgical Pathological Department, São João Hospital, 4200-319 Porto, Portugal \\ ${ }^{4}$ Department of Surgical Pathology, Faculty of Medicine, Porto University, 4099-002 Porto, Portugal \\ ${ }^{5}$ Clinical Hematology Department, São João Hospital, 4200-319 Porto, Portugal
}

Correspondence should be addressed to Ramon Andrade Bezerra de Mello, ramondemello@gmail.com

Received 2 September 2010; Accepted 25 October 2010

Academic Editor: Robert Peter Gale

Copyright (C) 2010 Ramon Andrade Bezerra de Mello et al. This is an open access article distributed under the Creative Commons Attribution License, which permits unrestricted use, distribution, and reproduction in any medium, provided the original work is properly cited.

\begin{abstract}
Background. Hemophagocytic syndrome (HPS) is characterized by a hyperinflammatory reaction followed by alteration in cytotoxic function of Th1 lymphocytes and natural killer cells. We report a rare case of a patient that presented with fever and pancytopenia due to HPS associated with Hodgkin's lymphoma (HL). Case Report. A 69-year-old Caucasian woman was admitted presenting with complaints of fever, seizures, and low back pain that had lasted for two weeks. Laboratorial data showed pancytopenia. Bone marrow biopsy revealed infiltration by Reed-Sternberg cells and hemophagocytosis signs. Imaging studies showed mediastinal lymph nodes (stage IV B). She had been treated with ABVD (doxorubicin, bleomycin, vinblastine, and dacarbazine) followed by a good response. Conclusion. HPS associated with HL is a very rare and lethal disease, with mortality rates of about $15 \%$ to $60 \%$. The prompt diagnosis of the underlying lymphoma may be an important strategy for optimizing the clinical approach and outcome.
\end{abstract}

\section{Introduction}

Hemophagocytic syndrome (HPS) is characterized by the proliferation of benign macrophages responsible for extensive phagocytosis of hematopoietic cells due to a hyperinflammatory reaction that may cause alteration in cytotoxic function of T lymphocytes and natural killer cells $[1,2]$. One of the most consistent findings is low or absent cytotoxicity activity of natural killer (NK) cells. This biological event is related to a defective production of cytokines and anomalous inflammatory reaction that change the normal behavior of the immune system leading to deregulated cell signaling. Some studies suggest that the lack of perforins, a hydrophobic protein that is packaged into specialized cytotoxicity granules of human natural killer cells (CD56 low, $\left.\mathrm{CD} 8^{-}\right)$, natural killer $\mathrm{T}$ cells $\left(\mathrm{CD} 56^{\text {low }}, \mathrm{CD}^{\text {+low }}\right)$, and activated $\mathrm{CD}^{+} \mathrm{T}$ helper 1 lymphocytes (Th1), results in insufficiency to regulate or terminate a immune response $[1,3-5]$. These perforins seem to act with granzymes, a serine protease, leading to induced apoptosis in the target cells. Mutation in the perforin gene accounts for about $20 \%-$ $40 \%$ of hemophagocytic lymphohistiocytosis subjects $[3,6]$. HPS is a clinical pathological disease described by histiocytic proliferation, fever, hepatosplenomegaly, cytopenia, altered liver function, hyperferritinemia, hypertriglyceridemia, low plasma fibrinogen levels, and/or frequently coagulopathy disorders $[1,3,4,7]$. It can be genetic, when associated with inherited alteration of $\mathrm{T}$ lymphocytes and NK cells behavior, or acquired, associated with infection, mainly Epstein-Barr virus (EBV), autoimmune, or immunodeficiency status. It is rarely associated with $\mathrm{B}$ cell lymphoma $[1,4]$. The treatment is very difficult, and some studies $[3,4,8]$ report a bad therapeutic prognosis sometimes, with a clinical response to chemotherapy rate of about $65 \%$ [4]. In this paper, we 
report a rare case of a patient that first presented with fever and pancytopenia due to hemophagocytosis associated with Hodgkin's lymphoma (HL) and highlight the difficulties regarding diagnosis and clinical approach.

\section{Case Report}

A 69-year-old Caucasian woman was admitted to the internal medicine ward presenting with symptoms of fever, seizures, and low back pain that had lasted for two weeks, followed by asthenia and dyspnea on moderate exertion. She had a medical history of probable inflammatory oculomotor palsy (under chronic corticotherapy), systemic arterial hypertension, dyslipidemia, obesity, and hyperhomocysteinemia. She had irrelevant familial history, without consanguineous parents. On physical examination, she had good performance status, left ptosis, left oculomotor palsy, no palpable lymph node, normal cardiopulmonary and abdominal examinations, and no peripheral edemas. The subsequent laboratorial study revealed pancytopenia, hyperglycemia, hypertriglyceridemia, hyperferritinemia, low fibrinogen levels, and high $\beta-2$ microglobulin levels (Table 1). The thoracicabdominal computed tomography (CT) showed mediastinal lymph nodes swelling between 12 and $15.5 \mathrm{~mm}$ and mild hepatosplenomegaly. The bone marrow biopsies revealed marrow infiltration by Hodgkin's lymphoma with ReedSternberg cells and hemophagocytosis signs (Figure 1) (stage IV B by Ann Arbor). The patient was submitted to highdose corticotherapy followed by chemotherapy (ABVDdoxorubicin, bleomycin, vinblastine, and dacarbazine). She had an allergic reaction to bleomycin, which was changed to cyclophosphamide. On discharge the patient retained good clinical status, without fever and other complains.

\section{Discussion}

Hodgkin's disease was first macroscopically described by Thomas Hodgkin in 1832 as a primary nodal lymphoproliferative disorder. In 1898 and 1902, Carl Sternberg and Dorothea Reed, respectively, reported the characteristic binucleated and multinucleated dysplastic giant cells located in an abundant cellular background that came to be called Reed-Sternberg cells. After 1990s, immunophenotyping and clinical data showed that this pathology basically had two distinct entities: nodular lymphocyte-predominant Hodgkin's lymphoma and classic Hodgkin's lymphoma [9]. The hemophagocytic syndrome is a very rare and lethal disease. It was first described by Scott and Robb-Smith in 1932 who named it "histiocytic medullary reticulosis". In 1979, Riscall et al. first characterized virus-associated HPS in a case series of 19 patients. Due to the difficulty to express a correct diagnosis, the incidence of HPS is difficult to estimate; a Japanese study group has reported an annual incidence of about 1 in $800.000[1,10]$. The mortality rate is about $15 \%$ to $60 \%$. HPS may be associated with EBV virus in $20 \%-80 \%$ of cases, and it is predominant in males. The EBV infection is consistently associated with $\mathrm{HL}$, and older patients with this situation have a poor prognosis and, in general, tolerate
TABLE 1: Laboratorial data on admission to internal medicine ward: blood analysis.

\begin{tabular}{|c|c|c|}
\hline Laboratorial data & Values & $\begin{array}{c}\text { Reference } \\
\text { values }\end{array}$ \\
\hline Hemoglobin & $7.6 \mathrm{~g} / \mathrm{dL}$ & $12-16$ \\
\hline Hematocrit & $23.8 \%$ & $37-49$ \\
\hline Leucocyte count & $1.17 \times 10^{9} / \mathrm{L}$ & $4.0-11.0$ \\
\hline Neutrophils & $65 \%$ & $53.8-69.8$ \\
\hline Lymphocyte & $16.2 \%$ & $25.3-47.3$ \\
\hline Platelets & $49 \times 10^{9} / \mathrm{L}$ & $180-500$ \\
\hline Albumin & $33.5 \mathrm{~g} / \mathrm{L}$ & $38-51$ \\
\hline Total protein & $53.8 \mathrm{~g} / \mathrm{L}$ & $64-83$ \\
\hline $\begin{array}{l}\text { AST (aspartate } \\
\text { aminotransferase) }\end{array}$ & $45 \mathrm{U} / \mathrm{L}$ & $10-31$ \\
\hline ALT (alanine aminotransferase) & $105 \mathrm{U} / \mathrm{L}$ & $10-31$ \\
\hline Gama glutamyltransferase & $719 \mathrm{U} / \mathrm{L}$ & $7-32$ \\
\hline Alkaline phosphatase & $274 \mathrm{U} / \mathrm{L}$ & $38-145$ \\
\hline Total Bilirrubin & $24.6 \mathrm{mg} / \mathrm{L}$ & $<12$ \\
\hline $\begin{array}{l}\text { LDH (lactate dehydrogenase) } \\
\text { seric }\end{array}$ & $417 \mathrm{U} / \mathrm{L}$ & $135-225$ \\
\hline Prothrombin time & 12.8 Seconds & $10.5-13.5$ \\
\hline $\begin{array}{l}\text { Activated partial thromboplastin } \\
\text { time }\end{array}$ & 28.3 Seconds & $24.5-36.5$ \\
\hline Fibrinogen level & $178 \mathrm{mg} / \mathrm{dL}$ & $190-400$ \\
\hline Glucose & $250 \mathrm{mg} / \mathrm{dL}$ & $75-115$ \\
\hline Urea & $59 \mathrm{mg} / \mathrm{dL}$ & $10-50$ \\
\hline Creatinine & $0.91 \mathrm{mg} / \mathrm{dL}$ & $0.6-1.0$ \\
\hline Ferritin & $9606.00 \mathrm{ng} / \mathrm{mL}$ & $14.0-233$ \\
\hline Triglycerides & $6.36 \mathrm{~g} / \mathrm{L}$ & $<1.50$ \\
\hline C-reactive protein & $5.5 \mathrm{mg} / \mathrm{L}$ & $<3.0$ \\
\hline$\beta-2$ microglobulin & $6620 \mathrm{~g} / \mathrm{L}$ & $700-3400$ \\
\hline
\end{tabular}

current treatments less well than young patients [11]. Some papers hypothesize that the latent membrane protein (LPM1) released by tumor cells infected by EBV may induce the production of large amounts of Th1 cytokines by ReedSternberg cells, leading to hemophagocytosis $[1,6]$. These mechanisms could be responsible for intracellular signaling that regulates the apoptosis and macrophage recruitment resulting in cell destruction, but it is still not clear [6]. Bhagwati et al. reported that the clinical manifestation of HPS is a result of a variable elevation of various inflammatory cytokines including interferon- $\gamma$ (IFN- $\gamma)$, tumor necrosis factor- $\alpha$ (TNF- $\alpha)$, interleukin- $1 \beta$ (IL-1 $\beta$ ), soluble interleukine 2 receptor, and linterleukin-6 (IL-6) leading to a systemic inflammatory response syndrome [12]. In 2005 Mazodier et al. reported that low levels of interleukin 18 may be associated with secondary HPS in patients with underlying disease, because it is a strong inducer of Th-1 response, IFN- $\gamma$ production, and stimulation of macrophages and NK cells [13]. In 2010, Aldinucci et al. reported that the nuclear factor- $\kappa \beta(\mathrm{NF}-\kappa \beta)$ and an altered JAK-STAT signaling pathway are part of the biological mechanisms associated with the inflammatory response of Hodgkin's disease, indirectly 


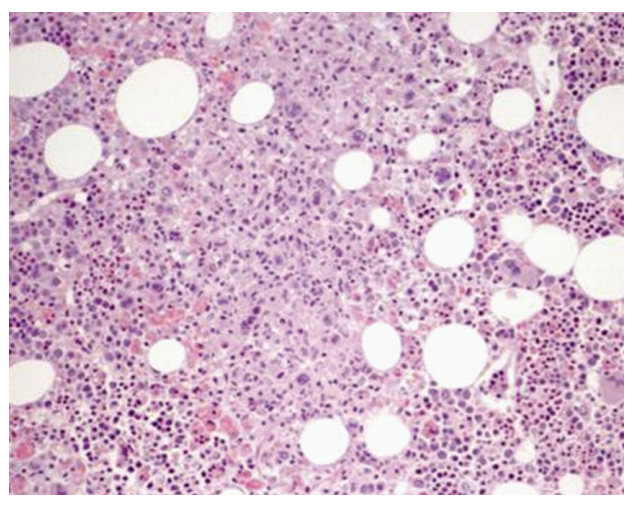

(a)

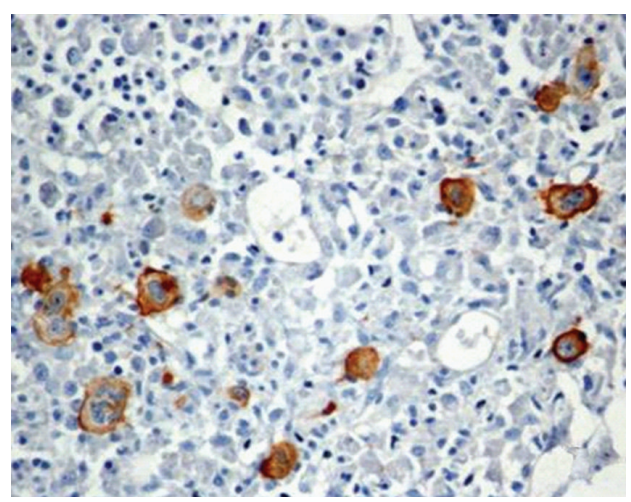

(c)

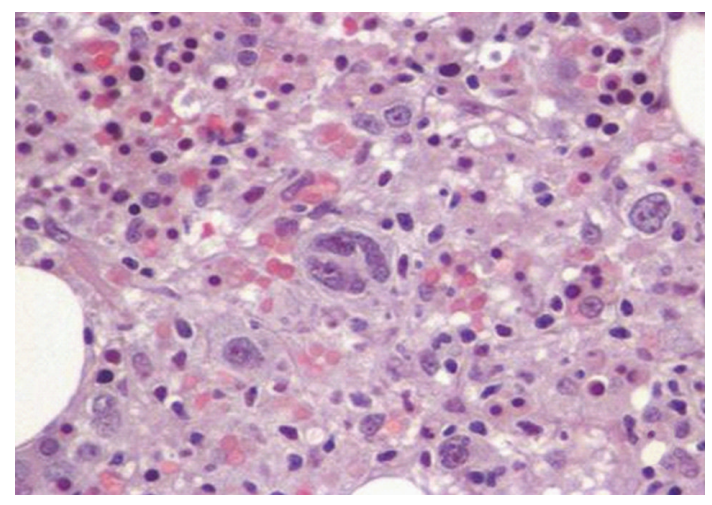

(b)

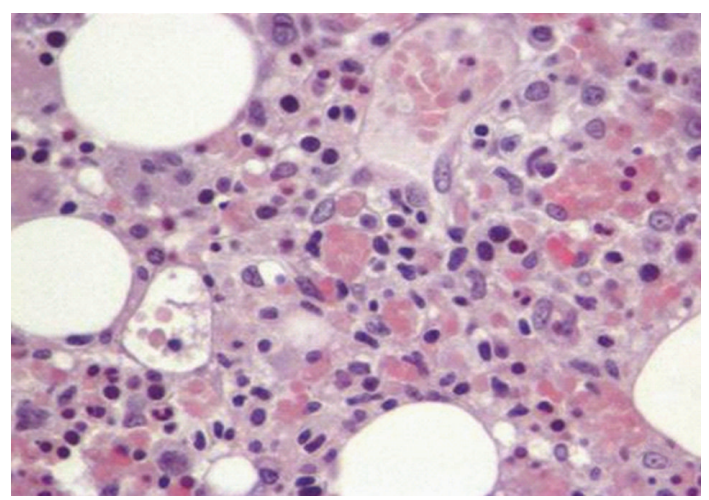

(d)

FIgure 1: Bone marrow biopsies revealing Hodgkin's disease and hemophagocytosis. (a) Hematoxylin and eosin (HE $\times 100)$, showing the general aspect of bone marrow. (b) HE $\times 600$, showing the Reed-Sternberg cells. (c) Blade positive to CD30. (d) HE $\times 600$, showing in the center of figure the hemophagocytosis signs: the macrophage with erythrocytes inside.

helping to regulate the cell death. The overexpression of the members of the TNF receptor family, like CD30 and CD40, is a hallmark of Hodgkin and Reed-Sternberg cells [14]. To confirm diagnosis of acquired HPS, five out of eight criteria should exist: fever, splenomegaly, cytopenia in more than two cell lines (hemoglobin $<90 \mathrm{~g} / \mathrm{L}$ or neutrophils $<1 \times 10^{9} / \mathrm{L}$, e.g.), hypertriglyceridemia (fasting triglycerides more than $3 \mathrm{mmol} / \mathrm{L})$ and/or hypofibrinogenemia $(<1.5 \mathrm{~g} / \mathrm{L})$, ferritin more than $500 \mathrm{ug} / \mathrm{L}$, soluble $\mathrm{CD} 25 \geq 2400 \mathrm{U} / \mathrm{mL}$, decreased or absent NK cell activity, and hemophagocytosis in bone marrow or lymph nodes. In this case the patient had almost all of these criteria including the bone marrow alteration [15]. The main point of HPS treatment is to suppress the hyperinflammation that is responsible for threatening the patient's life and treat the principal cause of this stimulus. The corticosteroids are of fundamental importance in reducing cytokine release and inhibiting the inflammatory reaction. In 2010, Herbst et al. reported that the combination of radiotherapy and chemotherapy with ABVD may improve the tumor control and 5-year overall survival in patients with early stage Hodgkin's lymphoma, which was not the case with our patient. However, it is important to note that cardiac toxicity is associated with mediastinal radiation and with cumulative dose of chemotherapy, in particular doxorubicin [8]. The optimal treatment for patients with
Hodgkin's disease and HPS has not yet been established. ABVD chemotherapy seems a reasonable choice. Patients with poorly responsive disease may be suitable for allogeneic hematopoietic stem cell transplantation with reduced intensity conditioning in order to avoid transplant-related complications and prevent sequential relapse [16].

\section{Conclusion}

Acquired hemophagocytic syndrome associated with Hodgkin's lymphoma is a rare, fatal, and sometimes underdiagnosed disease, frequently triggered by viral infections or in association with inflammatory disease $[10,17]$. Thus, the prompt diagnosis of the underlying lymphoma is the most important strategy for optimizing the clinical approach and improving the outcome. Therefore, it is important that physician should be alert to and suspect this pathology in cases of patients with unexplained fever, organomegaly, and blood count alteration, such as cytopenia with more than two lines, even if there are no palpable lymph nodes.

\section{Conflict of Interests}

The authors declare that they have no conflict of interests. 


\section{Consent}

Written informed consent was obtained from the patient for publication of this case report and accompanying images. A copy of the written consent is available for review by the Editor-in-Chief of this journal.

\section{References}

[1] F. Ménard, C. Besson, P. Rincé et al., "Hodgkin lymphomaassociated hemophagocytic syndrome: a disorder strongly correlated with Epstein-Barr virus," Clinical Infectious Diseases, vol. 47, no. 4, pp. 531-534, 2008.

[2] M. Szyper-Kravitz, "The hemophagocytic syndrome/macrophage activation syndrome: a final common pathway of a cytokine storm," The Israel Medical Association Journal, vol. 11, no. 10, pp. 633-634, 2009.

[3] J. W. Verbsky and W. J. Grossman, "Hemophagocytic lymphohistiocytosis: diagnosis, pathophysiology, treatment, and future perspectives," Annals of Medicine, vol. 38, no. 1, pp. 20 31, 2006.

[4] A.-R. Han, H. R. Lee, B.-B. Park et al., "Lymphoma-associated hemophagocytic syndrome: clinical features and treatment outcome," Annals of Hematology, vol. 86, no. 7, pp. 493-498, 2007.

[5] M. Durand, Y. Troyanov, P. Laflamme, and G. Gregoire, "Macrophage activation syndrome treated with anakinra," The Journal of Rheumatology, vol. 37, no. 4, pp. 879-880, 2010.

[6] D. Benharroch, I. Einav, A. Feldman, A. Levy, S. Ariad, and J. Gopas, "Apoptosis of Hodgkin-Reed-Sternberg cells in classical Hodgkin lymphoma revisited," APMIS, vol. 118, no. 5, pp. 339-345, 2010.

[7] H. Kojima, N. Takei, H. Y. Mukai et al., "Hemophagocytic syndrome as the primary clinical symptom of Hodgkin's disease," Annals of Hematology, vol. 82, no. 1, pp. 53-56, 2003.

[8] C. Herbst, F. A. Rehan, C. Brillant et al., "Combined modality treatment improves tumor control and overall survival in patients with early stage Hodgkin's lymphoma: a systematic review," Haematologica, vol. 95, no. 3, pp. 494-500, 2010.

[9] H. Stein and R. Bob, "Is hodgkin lymphoma just another Bcell lymphoma?" Current Hematologic Malignancy Reports, vol. 4, no. 3, pp. 125-128, 2009.

[10] N. R. Maakaroun, A. Moanna, J. T. Jacob, and H. Albrecht, "Viral infections associated with haemophagocytic syndrome," Reviews in Medical Virology, vol. 20, no. 2, pp. 93-105, 2010.

[11] R. F. Jarrett, G. L. Stark, J. White et al., "Impact of tumor Epstein-Barr virus status on presenting features and outcome in age-defined subgroups of patients with classic Hodgkin lymphoma: a population-based study," Blood, vol. 106, no. 7, pp. 2444-2451, 2005.

[12] N. S. Bhagwati, S. J. Oiseth, L. S. Abebe, and P. H. Wiernik, "Intravascular lymphoma associated with hemophagocytic syndrome: a rare but aggressive clinical entity," Annals of Hematology, vol. 83, no. 4, pp. 247-250, 2004.

[13] K. Mazodier, V. Marin, D. Novick et al., "Severe imbalance of IL-18/IL-18BP in patients with secondary hemophagocytic syndrome," Blood, vol. 106, no. 10, pp. 3483-3489, 2005.

[14] D. Aldinucci, A. Gloghini, A. Pinto, R. De Filippi, and A. Carbone, "The classical Hodgkin's lymphoma microenvironment and its role in promoting tumour growth and immune escape," The Journal of Pathology, vol. 221, no. 3, pp. 248-263, 2010.
[15] G. E. Janka, "Familial and acquired hemophagocytic lymphohistiocytosis," European Journal of Pediatrics, vol. 166, no. 2, pp. 95-109, 2007.

[16] Y.-H. Chang, P.-J. Lu, M.-Y. Lu, J.-S. Wang, C.-L. Tung, and C.-F. Shaw, "Sequential transplants for respective relapse of hodgkin disease and hemophagocytic lymphohistiocytosis: a treatment dilemma," Journal of Pediatric Hematology/Oncology, vol. 31, no. 10, pp. 778-781, 2009.

[17] M. Machaczka, J. Vaktnäs, M. Klimkowska, H. Nahi, and H. Hägglund, "Acquired hemophagocytic lymphohistiocytosis associated with multiple myeloma," Medical Oncology, vol. 27, pp. 1-5, 2010. 


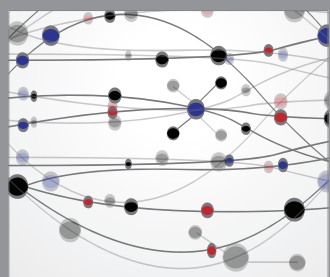

The Scientific World Journal
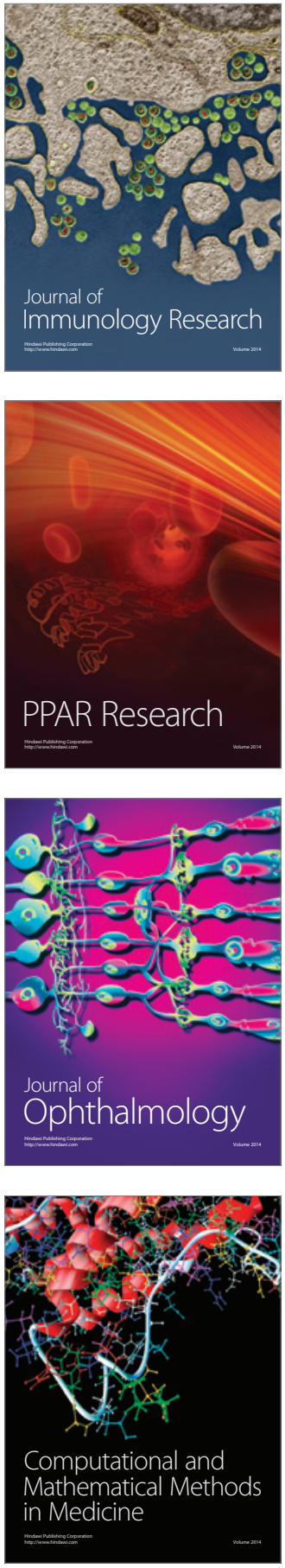

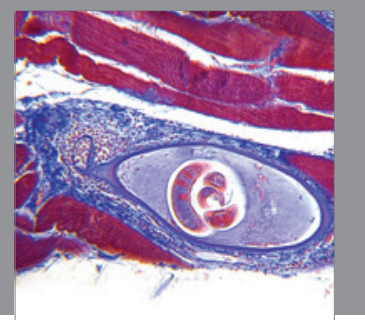

Gastroenterology

Research and Practice
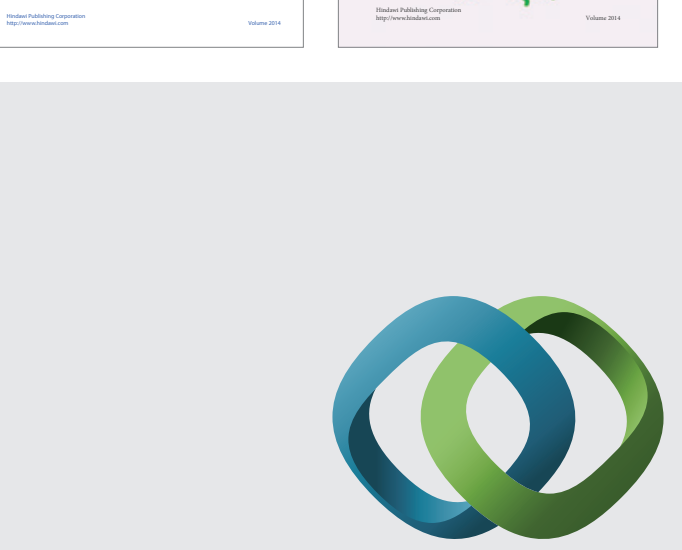

\section{Hindawi}

Submit your manuscripts at

http://www.hindawi.com
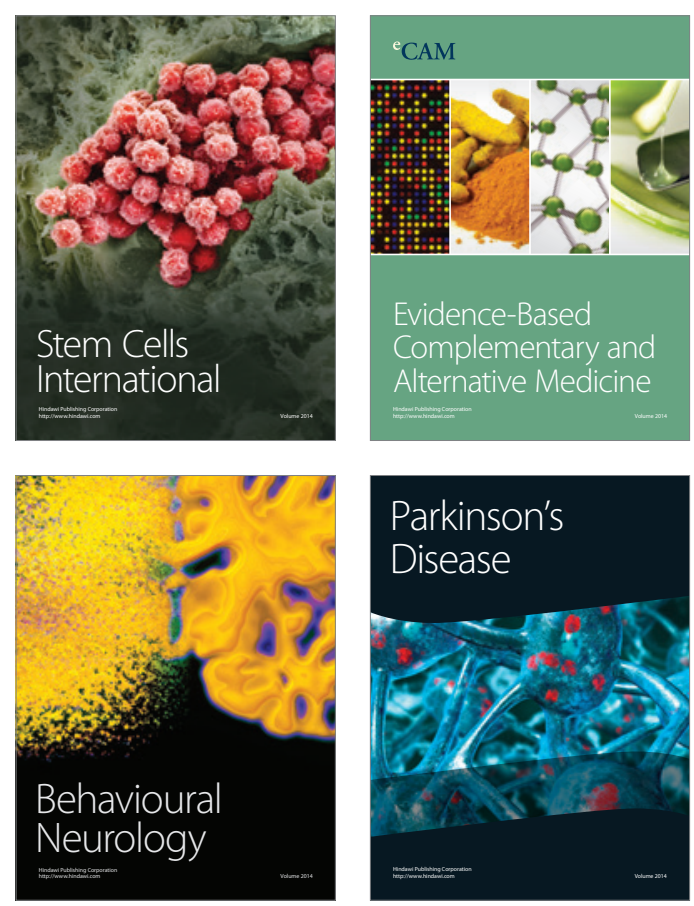

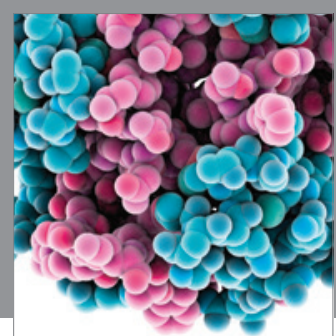

Journal of
Diabetes Research

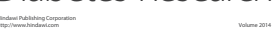

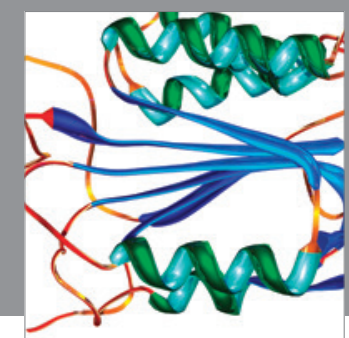

Disease Markers
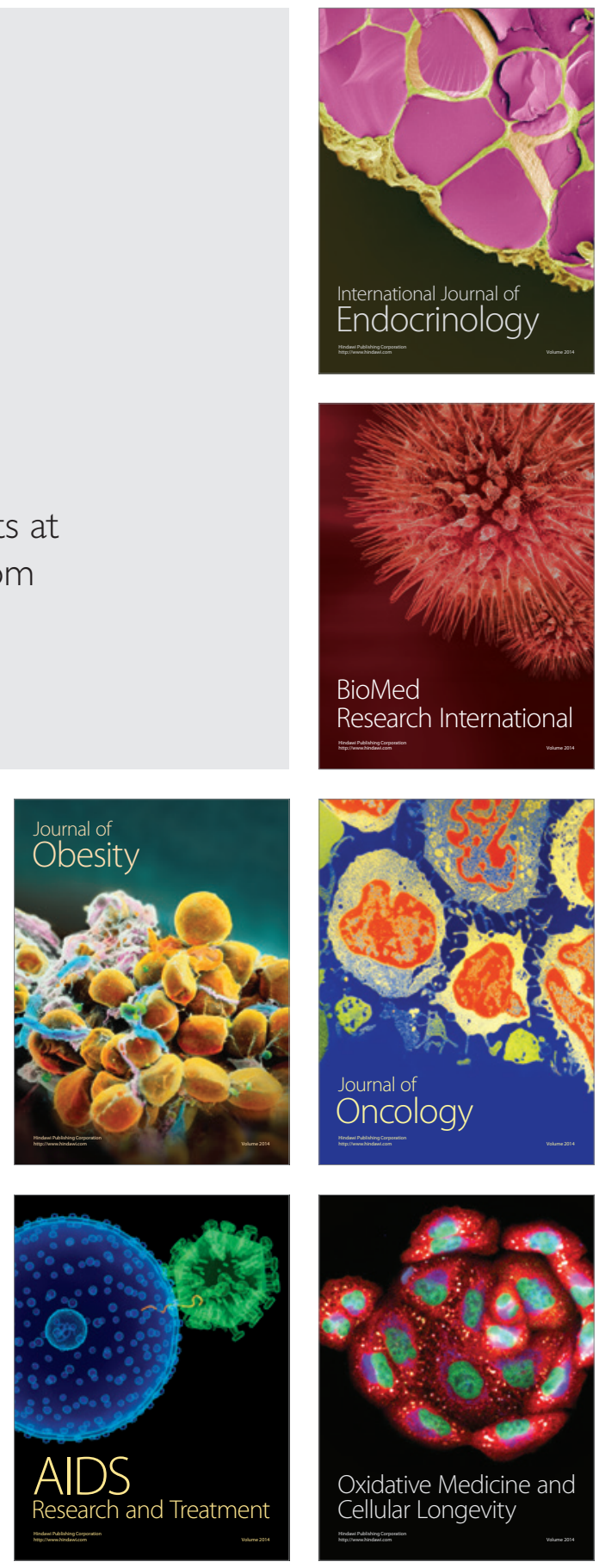